Review Article

\title{
Therapeutic Potential of Quercetin as an Antiatherosclerotic Agent in Atherosclerotic Cardiovascular Disease: A Review
}

\author{
Qian Deng $(\mathbb{D}$, Xiao Xue Li, Yanting Fang, Xin Chen, and Jingui Xue $(\mathbb{D}$ \\ Shuguang Hospital Affiliated to Shanghai University of Traditional Chinese Medicine, Shanghai, China \\ Correspondence should be addressed to Jingui Xue; xuejingui@sina.com
}

Received 14 November 2019; Revised 31 March 2020; Accepted 2 May 2020; Published 4 June 2020

Academic Editor: Francisco Solano

Copyright (c) 2020 Qian Deng et al. This is an open access article distributed under the Creative Commons Attribution License, which permits unrestricted use, distribution, and reproduction in any medium, provided the original work is properly cited.

\begin{abstract}
Atherosclerotic cardiovascular disease (ASCVD) is one of the diseases with the highest morbidity and mortality globally. It causes a huge burden on families and caregivers and high costs for medicine and surgical interventions. Given expensive surgeries and failures of most conventional treatments, medical community tries to find a more cost-effective cure. Thus, attentions have been primarily focused on food or herbs. Quercetin $(\mathrm{Qu})$ extracted from food, a flavonoid component, develops potentials of alternative or complementary medicine in atherosclerosis. Due to the wide range of health benefits, researchers have considered to apply $\mathrm{Qu}$ as a natural compound in therapy. This review is aimed to identify the antiatherosclerosis functions of Qu in treating ASCVD such as anti-inflammatory, antioxidant properties, effects on endothelium-dependent vasodilation, and blood lipid-lowering.
\end{abstract}

\section{Introduction}

Atherosclerosis (AS) is a chronic progressive inflammatory disease associated with inflammatory response, endothelial dysfunction, lipid metabolism disorders, smooth muscle cell migration and proliferation, and oxidative stress $[1,2]$. Atherosclerotic cardiovascular disease (ASCVD) caused by AS is one of the diseases with the highest morbidity and mortality in the world, ranking first in the total cause of death among urban and rural residents in China, with more than $40 \%$ mortality rate, whose incidence and number of cases are still rising [3]. Although the study shows that in the past 30 years, the incidence of coronary heart disease in the United States has dropped from $6.9 \%$ to $5.2 \%$, the mortality rate due to coronary heart disease has dropped $60 \%$, and ASCVD has been and will continue to be the leading cause of death among US residents [4]. Therefore, the treatment of ASCVD is a hot topic concerned by the public. In recent years, a number of research achievements have been made in the field of atherosclerosis [5]. Various medicines, such as HMG-CoA reductase inhibitors (statins) [6], cholesteryl ester transfer protein (CETP) inhibitors (anacetrapib) [7], and cholesterol absorption inhibitors (ezetimibe) [8], have been clinically proven in the treatment of atherosclerosis.
Antimyocardial ischemia drugs, coronary angioplasty, coronary stent implantation, and surgical coronary artery bypass grafting have been widely used to treat ASCVD.

Beyond modern medical treatment, the conventional medicine featured by natural herbs with satisfactory clinical efficacy and low toxicity can be used as replacement therapies for many diseases. Relevant research has become a hot topic in modern medicine [9-11]. Natural products like flavonoids which have been proved to have many functions such as anticancer [12], anti-inflammatory [13], antidiabetes [14], antivirus, and antiallergy [15] are considered as important resources in the treatment of cardiovascular disease. It has been widely reported that Quercetin $(\mathrm{Qu})$, as one of the important flavonoids, plays an important role in the prevention and treatment of atherosclerosis. Many biological targets of $\mathrm{Qu}$ have been discovered, for instance, inhibiting the formation of reactive oxygen species by blocking nicotinamide-adenine dinucleotide phosphate (NADPH) oxidase [16], preventing the formation of atherosclerotic plaques by upregulating nitric oxide synthetase [17] and stabilizing endothelial atherosclerotic plaque by downregulating matrix metalloproteinase-1 (MMP-1) [18]. Qu serves as one of the important type of flavonoids and is apparently capable of delivering anticipated antiatherosclerotic 
effects in ASCVD. Research interest for Qu is because of its diverse range of biological properties. For this review, we have assessed the literature which have been published in PubMed and the Web of Science related to AS or ASCVD in recent years to uncover the protective roles of $\mathrm{Qu}$ in antiatherosclerosis and ASCVD. The combined functions of $\mathrm{Qu}$ allow for the prevention of AS. This review describes the possible therapeutic benefits of $\mathrm{Qu}$, along with its potential mechanisms of action, to support the clinical use of the $\mathrm{Qu}$ for the prevention of ASCVD via antiatherosclerosis.

\section{Pharmacology and Bioavailability of Quercetin}

Quercetin $\left(3,3^{\prime}, 4^{\prime}, 5,7\right.$ pentahydroxy flavone) is one of a group of over 4000 naturally available plant phenolic compounds whose isolation and biological recognition were first described by Rusznyak and Szent-Györgyi in 1936 [19]. Its chemical structure is an unconjugated aglycone that does not have a carbohydrate moiety and consists by a fused ring system with a benzopyran associated with an aromatic ring and phenyl substituents (the chemical structure is shown in Figure 1). Qu is the most common and widely distributed flavonol compound in our regular diet. This situation is shown in Figure 2. It can be found in almost all plant food, such as tea, onion, lettuce, broccoli, beans, fruits, and buckwheat, and it is also one of the effective components of gingko leaves, mulberry parasitic, sandalwood, and other Chinese herbs [20-22]. The natural flavonol exists in a glycosylated form generally with glucose as its corresponding sugar part. Glycosylation may occur at any of the five $\mathrm{OH}$ groups of the flavonol ring additional types of $\mathrm{Qu}$ are usually $\mathrm{Qu}$ aglycone, such as $\mathrm{Qu}$ 3-O-glucuronide and $\mathrm{Qu} 3^{\prime}$-O-sulfate [23], all kinds of $\mathrm{Qu}$ are consumed in the small intestine and digestive tract, the most widely recognized Qu glycoside exhibits the sugar moiety and structures speak to $60-75 \%$ of flavonoid intake [24]. With the development of research, modern research has confirmed that $\mathrm{Qu}$ has exhibited high antioxidative, anti-inflammatory, and antimicrobial activities [25]. Besides, recent studies have found that $\mathrm{Qu}$ can restrain the proliferation and metastasis of multiple cancer cell types, such as breast cancer [26], colon cancer [27], lung cancer [28], and pancreatic cancer cells [29].

$\mathrm{Qu}$ has a long history of cardioprotective ability, and it has been extended for clinical trials. In addition to its wellknown heart-protecting effects, Qu has also been reported to exert various other pharmacological activities such as anxiolytic [30], hypoglycemic [31], immunomodulatory [32], neuromodulation [33], and wound healing [34]. However, poor water solubility and low bioavailability of Qu have been its limitations. Qu is quickly conjugated with glucuronic acid and/or sulfate during first-pass metabolism (intestine-liver), and a portion of the metabolites is also methylated; the first investigation on the pharmacokinetics of $\mathrm{Qu}$ in humans suggested very poor oral bioavailability after a single oral dose ( 2\%) [35]. The estimated absorption of Qu glucoside, the naturally occurring form of $\mathrm{Qu}$, ranges from $3 \%$ to $17 \%$ in healthy individuals receiving $100 \mathrm{mg}$ [36]. Some modified

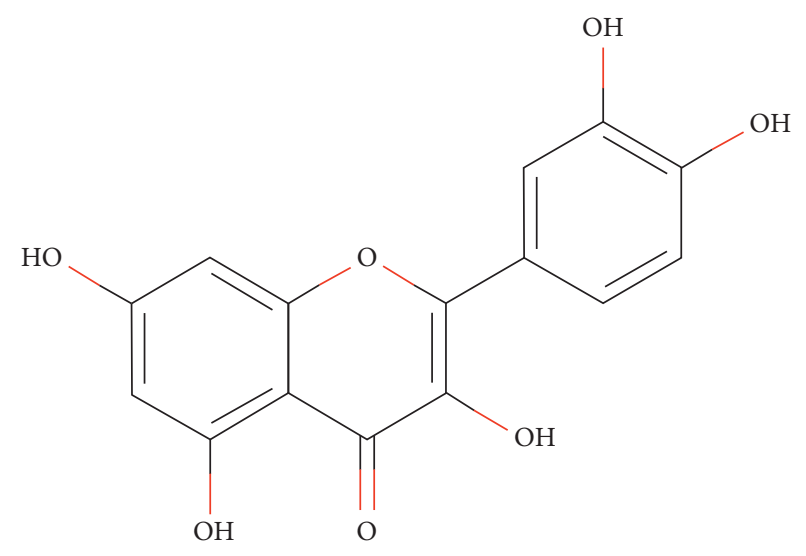

FIGURE 1: Compound structure of quercetin. Source: http://www. swisstargetprediction.ch.

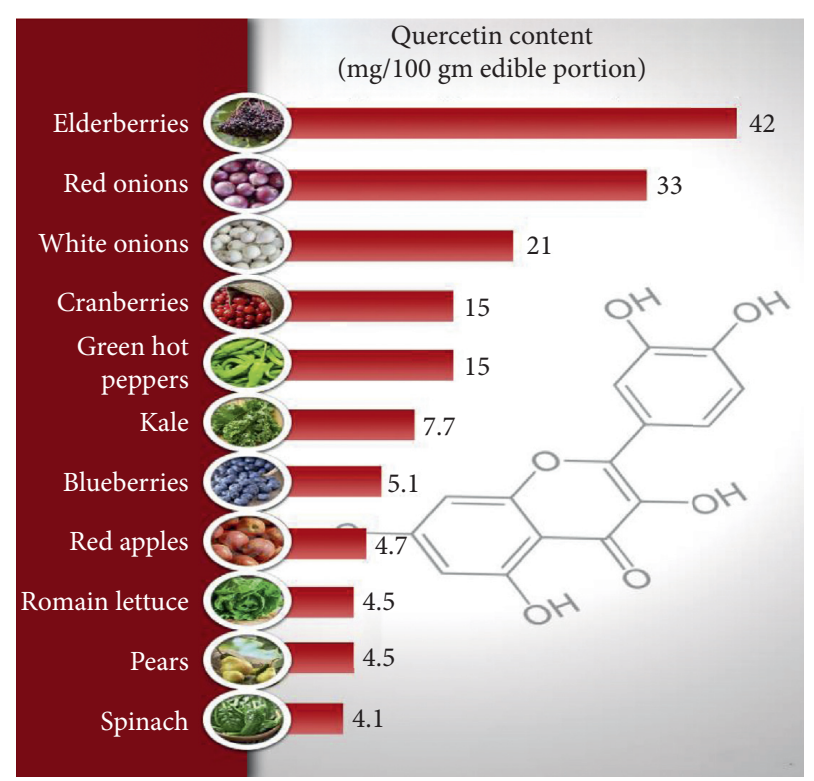

FIGURE 2: Quercetin content in different foods. Source: http:// drjockers.com.

dosage forms of $\mathrm{Qu}$ have been developed to overcome these disadvantages, mainly including nanoparticles [37], microemulsions [38], and other drug carriers [39].

\section{Role of Quercetin in Antiatherosclerosis}

\subsection{Protective Role in Endothelium Protection.} Endothelial cells are a semipermeable barrier between blood and vascular wall; it can locally regulate the blood vessels by secreting vasodilator substances such as nitric oxide (NO), prostacyclin, endothelium-derived hyperpolarizing factor, and vasoconstrictive substances such as endothelin, an endothelium-derived contractile factor [40]. These substances can dilate blood vessels, antiproliferate, antiagglutinate, and limit blood pressure in physiological situation, while they can destroy the endothelial homeostasis in pathological states, such as local elevated tensile stress, hypercholesterolemia, total triglyceride- (TG-) rich residual 
lipoproteins, circulation of vasoactive amines, and infection and immune complex [41]. Qu can relieve vascular endothelial injury through multiple approaches to play a part in antiatherosclerosis [42-44].

$\mathrm{NO}$ is an important endogenous vasodilator produced by endothelial nitric synthase (eNOS) acting on L-arginine, which can regulate vascular dilatation and endothelial function [40]. However, when the vascular endothelial cells are affected by a series of harmful factors, the release of vasomotor factors by the endothelial cells decreases, while vasoconstrictors increase, which breaks the vascular homeostasis and causes endothelial dysfunction and eventually leads to the occurrence of AS events [40]. Excessive NO can upregulate the expression of $\mathrm{Bcl}-2 / \mathrm{Bax}$ of mitochondrial through the intracellular Akt pathway, which inhibit the release of reactive oxygen species (ROS), cytochrome c, capase-9, and caspase-3. Qu can reverse the endothelial damage caused by excessive NO by inhibiting nitrification stress and protect endothelial cells [45]. Early studies have found that ATP can increase the shear stress generated by blood flow on vascular endothelial cells, increase the intracellular calcium concentration and the activity of eNOS, thus raise the production and release of $\mathrm{NO}$, and ultimately lead to AS [46]. Qu can inhibit the promoting effect of ATP on NO production in vascular endothelial cells, reduce intracellular calcium concentration and eNOS activity, and reduce vascular endothelial injury [42]. Impaired vascular homeostasis caused by decreased bioactivity of endogenous $\mathrm{NO}$ is the most typical pathophysiological feature of endothelial dysfunction [41]. Stabilizing intravascular homeostasis may be an important mechanism, for Qu plays a part in protecting vascular endothelial function.

Oxidative stress is the main cause of endothelial dysfunction, which can lead to an imbalance between endothelial cell membrane stability and permeability, impair the function of endocrine and paracrine, and increase the expression of adhesion molecules and the release of endogenous reactive oxygen species (such as superoxide anion and hydrogen peroxide) [47]. In vitro studies have shown that Qu can directly act as an antioxidant, effectively scavenge oxygen free radicals, and protect vascular endothelial function [48]. Oxidative stress induced by homocysteine (HCY) can lead to endothelial damage [49]. Qu can protect the vascular endothelium from oxidative stress induced by homocysteine by inhibiting lipid peroxidation, protein oxidation, and enzymatic reaction, reducing the level of malondialdehyde (MDA) and increasing the content of glutathione (GSH) in high HCY rats [50].

3.2. Lipid Metabolism-Modulating Properties. Dyslipidemia is the main risk factor of AS, including the increase of lipid level caused by total cholesterol (TC), TG, and LDL and the reduction of atherosclerotic lipid levels caused by HDL. Regulating the disorder of lipid metabolism and reducing lipid accumulation are important means to prevent and alleviate AS. In recent years, studies at home and abroad have found that $\mathrm{Qu}$ can regulate the metabolism of lipid substances. Some studies have shown that monosodium glutamate (MSG) induces oxidative stress and hepatotoxicity in rats [51] as well as changes the lipid profile of mice [52], and $\mathrm{Qu}$ can maintain normal cholesterol levels and prevent the formation of atherosclerotic plaques by treating the dyslipidemia caused by MSG [53]. Besides, Qu can regulate lipid metabolism by lowering the level of TC, TG, LDL, and VLDL in serum and tissues and increasing the content of HDL in serum and phospholipid in tissue [54]. The possible mechanisms of $\mathrm{Qu}$ regulating lipid metabolism is described as follows.

HMG-CoA (5-hydroxy-3-methylglutaryl-coenzyme A) reductase is the rate-limiting enzyme in cholesterol synthesis, and its catalytic substrate HMG-COA generating mevalonate is the rate-limiting step in the synthesis of cholesterol. HMG-CoA reductase activity can affect the cholesterol synthesis. It has been demonstrated that $\mathrm{Qu}$ can prevent the accumulation of lipid and glycoprotein components in myocardial infarcted rats by reducing the levels of cholesterol, triglycerides, and free fatty acids and decreasing the activity of plasma and liver HMG-CoA reductase [55]. Leptin is a protein hormone involved in the regulation of energy intake and expenditure by the body. Leptin is an important cytokine that plays a key role in regulating lipid metabolism, promoting inflammation, and accelerating aortic valve calcification in patients with coronary heart disease [56]. Mzhelskaya et al. found that $\mathrm{Qu}$ can reduce cholesterol levels and lipid levels in high fat and fructose diet rats by regulating leptin-mediated lipid reception [57]. But, the study does not directly clarify the attenuating effect of $\mathrm{Qu}$ on cholesterol synthesis; the possible mechanism is that $\mathrm{Qu}$ regulate the negative feedback mechanism between fat deposits and fat catabolism rate through leptin, thus promoting the process of lipid metabolism and glucose metabolism and reducing cholesterol intake in rats [57].

Reverse cholesterol transport (RCT) is a process of transporting cholesterol to the liver for further excretion, which can effectively remove excess cholesterol in cells. RCT of macrophages in atherosclerotic plaques is a critical mechanism of antiatherosclerosis. Liver $\mathrm{X}$ receptor $\alpha$ $(\mathrm{LXR} \alpha)$ [58], scavenger receptor B-I (SR-BI) [59], and ATPbinding transporter A1 (ABCA1) play a vital role in promoting macrophages RCT and maintaining intracellular cholesterol homeostasis. Many compounds and extracts of traditional Chinese medicine can act on different targets of RCT and exert antiatherosclerosis effect [60]. Qu could promote intracellular cholesterol efflux, upregulate the expression of SR-BI, and reduce the ability of high-density lipoprotein (HDL) to selectively acquire cholesterol in a dose and time-dependent manner, indicating its protective role in atherosclerosis [61]. Peroxisome proliferator-activated receptor $\gamma(\operatorname{PPAR} \gamma)$ and LXR $\alpha$ are important transcriptional factors for ABCA1. Qu-induced upregulation of ABCA1 and cholesterol efflux of macrophages may be mediated by increased expression levels of the PPAR $\gamma$ and LXR $\alpha$ genes $[62,63]$. It was shown that $\mathrm{Qu}$ can induce the expression of ABCA1 in THP-1 derived foam cells, enhance the apoA-Idependent cholesterol efflux, and reduce the risk of atherosclerosis [63]. The selective uptake of HDL-C into hepatocytes and steroidogenic cells is the last step of RCT, a 
process that promotes HDL-C clearance in the plasma. Low clearance of plasma HDL-C aggravates the development of AS while high clearance of plasma HDL-C impedes atherogenesis. A study found that $\mathrm{Qu}$ promotes the selective uptake of HDL-C by enhancing SR-BI expression through stimulating the PPAR $\gamma / \mathrm{LXR} \alpha$ pathway in HepG2 cells [61]. Besides, Qu can also affect the expression of $\operatorname{LXR} \alpha$ and ABCA1 through the p38-dependent pathway [64], proprotein convertase subtilisin/kexin type 9 (PCSK9) pathway [65], and cholesterol 7 alpha-hydroxylase (CYP7A1) pathway [66] to promote cholesterol efflux and reduce the risk of atherosclerosis.

Accumulation of foam cells and formation of lipid streaks are the early lesion characteristics of AS. Oxidized low-density lipoprotein (oxLDL) is thought to transform native lipoprotein into an antigenic factor that attracts monocyte-derived macrophages to the vascular wall, thereby initiating a convoluted immune response governed by inflammatory modulators [67]. Inhibiting low-density lipoprotein (LDL) oxidation of macrophages and foam cell formation are effective strategies of antiatherosclerosis. Mulberry leaf rich $\mathrm{Qu}$ inhibited the oxidation and lipid peroxidation of LDL and attenuated atherosclerosis [68]. An earlier study reported that $\mathrm{Qu}$ also targeted the oxLDL-independent pathway and lipopolysaccharide-dependent pathway of lipid droplet formation in macrophages and inhibited the reactive oxygen species production and interleukin (IL)-6 secretion, which indicated the antiatherosclerotic activity of $\mathrm{Qu}$ [69]. oxLDL can induce excessive production of reactive oxygen species and block the expression of lectin-like oxidized LDL receptor1 (LOX-1) in cultured macrophages, leading to lipid accumulation. It was demonstrated in cultured macrophages that Qu could ameliorate lipid deposition and overproduction of reactive oxygen species induced by oxLDL and block the expression of LOX-1 [18].

3.3. Anti-Inflammatory Activity. AS is a chronic inflammatory disease mediated by a network of proinflammatory cytokines. Macrophages are critical in the inflammatory response. OxLDL-activated macrophages can synthesize and secrete many growth factors and pro-inflammatory factors, such as platelet-derived growth factor, fibroblast growth factor, and tumor necrosis factor (TNF)- $\alpha$, IL-1, which can promote the growth of plaque and inflammatory response $[70,71]$. T cells entering the intima are activated by recognizing antigens presented by macrophages and dendritic cells, producing factors with strong atherogenic effects [2], such as gamma interferon, TNF, and lymphotoxin. There are multiple signaling pathways for $\mathrm{Qu}$ to inhibit the expression of inflammatory factors to stabilize atherosclerotic plaque, slow down the progression of atherosclerosis, and reduce the incidence of ASCVD.

A major signaling mechanism associated with atherosclerosis is the activation of NF- $\kappa \mathrm{B}$ family of transcription factors. NF- $\kappa \mathrm{B}$ is an oxidative stress-sensitive transcription factor that has been found in the early lesions of atherosclerosis [72]. The transcription of vascular cell adhesion molecule-1 (VCAM-1), intercellular adhesion molecule-1 (ICAM-1), and other adhesion molecules, such as E-selectin and P-selectin, is regulated and activated by NF- $\kappa \mathrm{B}$ [73]. These activated adhesion molecules help blood-borne cells to recruit to atherosclerotic lesions. Oral administration of $\mathrm{Qu}$ significantly suppressed the levels of IL- $1 \beta$, TNF- $\alpha$, and IL10 in serum and attenuated atherosclerotic plaque through decreasing the transcriptional activity of the NF- $\kappa \mathrm{B}$ in patients with coronary artery disease [74]. Qu also inhibited proatherogenic mediators such as ICAM-1 and VCAM-1 in oxLDL-induced smooth muscle cells [32] and downregulated expression of adhesion molecules and NF- $\kappa \mathrm{B}$ in TNF- $\alpha$-induced human aortic endothelial cells [75]. Another study demonstrated that $\mathrm{Qu}$ is effective to regulate the atherosclerotic inflammatory process by attenuating the NF$\kappa \mathrm{B}$ signaling pathway in endothelial cells and decrease the inflammatory process induced by hypercholesterolemic diet in atherosclerotic rats [32].

Phosphatidylinositol 3-kinase (PI3K) signaling is a multicell surface receptor that regulates cell proliferation, survival, and death. Akt activated by PI3K in response to growth factors or cytokines is an inactive cytoplasmic protein that is recruited to the plasma membrane. The activation of the PI3K/Akt pathway significantly promotes macrophage polarization, which stimulates or inhibits inflammatory responses [44]. Toll-like receptors (TLR) and ROS can mediate the activation of PI3K/Akt signaling pathway [76]. Qu significantly downregulated the elevated mRNA expression of TLRs and cytokine TNF- $\alpha$ in HCD-fed atherosclerotic rats in vivo [77]. As Qu possesses inhibition on both TLR-NF- $\kappa$ B signaling pathway and TLR-mediated MAPK pathway, it is evident that it could be used as a therapeutic agent to ameliorate atherosclerotic inflammation and improve ASCVD patients' symptoms [77]. Qu also displayed an inhibitory role in vitro in LPS-induced ROS production, inflammatory response, and apoptosis, which were linked with PI3K/AKT-regulated caspase-3 and NF- $\kappa \mathrm{B}$ activation and reduced the atherosclerotic plaque size in high fructose feeding-induced mice [78].

Activation of p38 can activate the expression of cytokines involved in proinflammatory signaling and local recruitment of immune cells, such as E-selectin [79], VCAM-1 [79], and chemokine monocyte chemoattractant protein 1 (MCP-1) [80]. Frei Balz's team found that Qu play an anti-inflammatory role in inhibiting the activation of $\mathrm{p} 38$, reducing the expression of E-selectin and ICAM-1 protein in human aortic endothelial cells induced by lipopolysaccharide [81]. $\mathrm{Qu}$ also delayed the progression of atherosclerosis by increasing phosphorylation of p38 by activating transforming growth factor beta kinase 1 and mitogenic kinase 3/6 [64].

3.4. Antiapoptosis Activity. Apoptosis is an important factor during atherosclerotic development. Autophagy protects vascular cells in plaques against oxidative stress and apoptosis by degrading damaged organelles, which is an effective response against inflammation and oxidative stress in AS plaque cells, and thus it plays an important role in the initiation and development of AS [82]. TNF- $\alpha$, IL-1 $\beta$, and IL-18 are the key inflammatory factors between autophagy and inflammation. A previous study revealed that $\mathrm{Qu}$ 


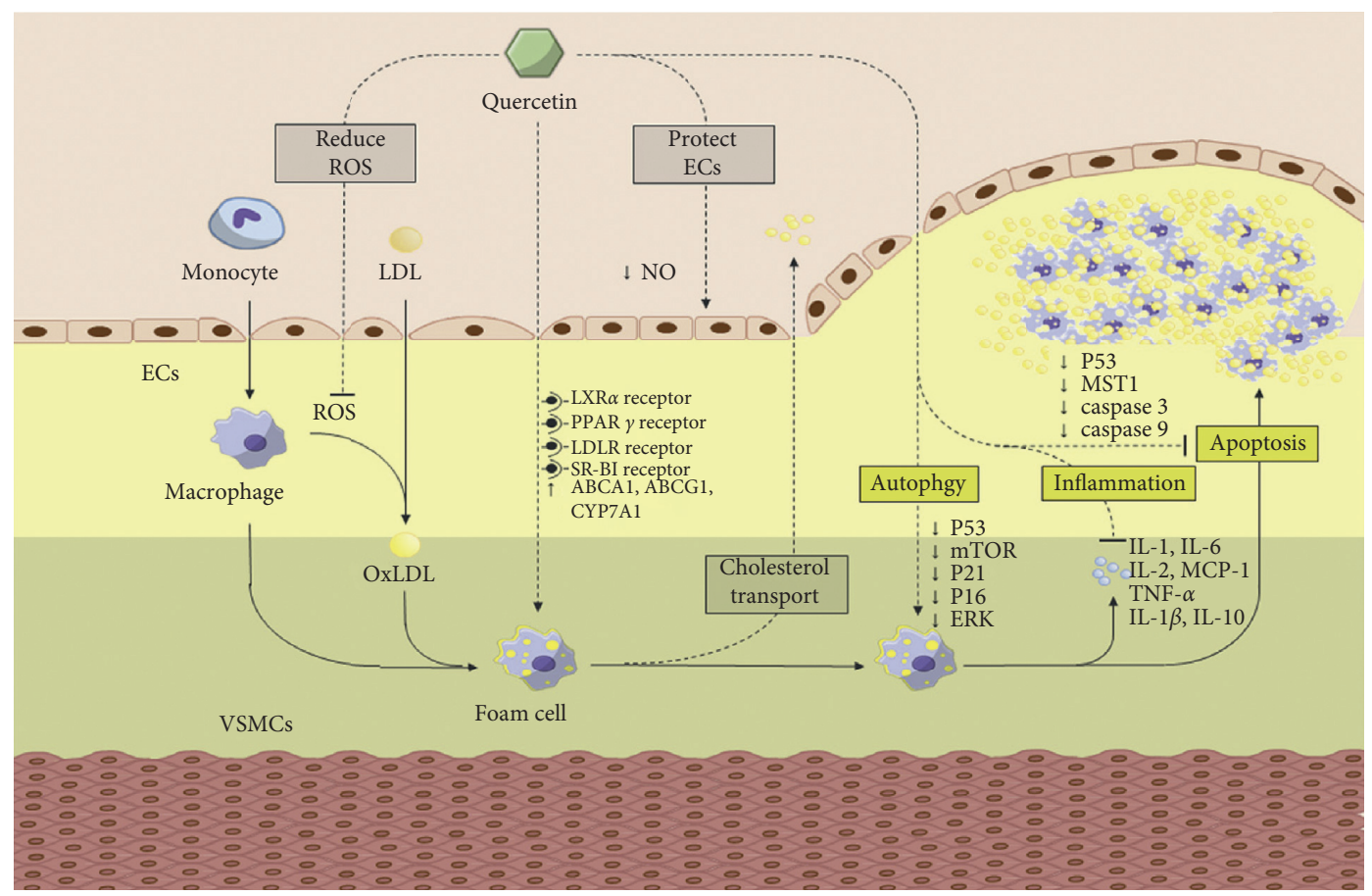

FIGURE 3: The possible pathway of quercetin on anti-atherosclerotic function.

stabilizes AS plaques and inhibits AS development by reducing the production of the proinflammatory cytokines TNF- $\alpha$, IL- $1 \beta$, and IL-18, a mechanism which involves the induction of autophagy [83]. Weakened autophagy takes place in all major cell types in AS plaques, resulting in impaired macrophage apoptosis and increased senescence of blood vessel endothelial and smooth muscle cells. mTOR, a key molecule in the process of autophagy induction, integrates multiple upstream signaling pathways and interacts with regulator proteins [84]. It also reported that $\mathrm{Qu}$ could downregulate the expression levels of mTOR, P53, and cyclin-dependent kinase inhibitor 1A (P21), enhance autophagy, and delay senescence [83]. Autophagy has also been termed as lipophagy, which involves the degradation of intracellular lipid droplets and contributes to cellular lipid metabolism [85]. Another study found that Qu effectively reduces oxLDL-induced RAW264.7 foam cell formation, reducing cellular lipid accumulation and delaying cell senescence through the MammalianSte20-like kinase1 (MST1) pathway [86]. MST1, a novel regulator of apoptosis, participates in multiple biological activities of cells, including autophagy, apoptosis, and oxidative stress [87, 88].

3.5. Alteration of the Gut Microbiota and Reduction of Atherogenic Lipid Metabolites. Recent studies of pathogenesis have highlighted the significant roles of the intestinal microbiota and chronic inflammation in both the onset and development of AS [89-91]. The occurrence of AS is strongly associated with inflammatory response caused by the disorder of the intestinal immune system [92]. AS patients have metabolic characteristics, for the community composition of their intestinal flora is different [93]. Inhibiting the inflammatory response and regulating the lipid metabolism of intestinal microorganisms can be used as strategies to delay the development of AS. Short-chain fatty acids (SCFAs) are metabolites of systemic inflammation and are associated with the expansion and rupture of AS plaques [94]; Qu can increase the concentration of SCFAs in the intestinal tract and inhibit the progression of AS [95]. A microbiome with high abundances of Firmicutes and Actinobacteria can result in atherosclerotic area [96, 97]; oral administration Qu reduced the levels of atherogenic lipid metabolites by modulating the abundances of Firmicutes and Actinobacteria [98].

3.6. Elimination of Etiology, Reduction of Complications, and Effective Prevention and Treatment of AS. In hemodynamically activated arterial regions, free radical-induced lipoprotein oxidation, enzymatic changes in the intima, production of active lipids, and increased enzymatic activity of MDA and ROS can increase the inflammatory response of arterial intima, thus causing atherosclerotic lesions [99]. Obesity and hypercholesterolemia increase the production of oxygen free radicals and cause oxidative stress [100]; Parvin et al. [101] found that $\mathrm{Qu}$ can reduce the blood lipid in obese rats, reduce the expression of oxidative stress factors, improve the vascular remodeling, and prevent the formation of atherosclerotic plaque through antioxidant activity.

In addition to the activities mentioned above, $\mathrm{Qu}$ also exerts antithrombotic activity both in vitro and in vivo [102, 103]. Isorhamnetin and tamarixetin inhibit platelet function and thrombus formation through effects on early activation processes including calcium mobilization, granule secretion, and integrin activation [104]. According to the recommendations of the ASCVD Global Guidelines, antiplatelet and antithrombotic treatment is a critical approach for the treatment of acute coronary artery syndrome and secondary prevention of 
TABLE 1: Summary of the main effects of quercetin on antiatherosclerosis in vivo.

\begin{tabular}{|c|c|c|c|}
\hline Effect & Subjects & Possible mechanism & Reference \\
\hline \multicolumn{4}{|l|}{ Animals } \\
\hline \multirow{4}{*}{ Endothelial protection } & Wistar rats & $\begin{array}{l}\text { Neutralize ROS, protect mitochondrial membrane, reduce LPO, and } \\
\text { increase GSH levels through the increased catalase activity }\end{array}$ & {$[109]$} \\
\hline & ApoE ${ }^{-/-}$mice & Regulate NADPH oxidase subunits expression & {$[16]$} \\
\hline & Sprague- & Increase GSH, erythrocyte CAT, and MDA levels & {$[50]$} \\
\hline & Wistar rats & $\begin{array}{l}\text { Decrease serum LDL, TC, MDA, and ROS to improve the vascular } \\
\text { structure and prevent from the plaque formation }\end{array}$ & {$[101]$} \\
\hline \multirow[b]{3}{*}{ Anti-inflammation } & $\mathrm{ApoE}^{-1-}$ mice & Decrease serum TNF- $\alpha$ and IL-6 levels and increase levels & {$[110]$} \\
\hline & $\mathrm{ApoE}^{-1-}$ mice & Inhibit phenotypic and functional maturation of DCs & {$[111]$} \\
\hline & $\mathrm{Balb} / \mathrm{c}$ mice & $\begin{array}{l}\text { Mediate HDL function and lipid-glucose state in the circulation by } \\
\text { improving biological activity (quality) and the activity of bound to } \\
\text { PON1 }\end{array}$ & [112] \\
\hline \multirow[b]{2}{*}{ Antiapoptosis } & Nude mice & Activate ERK and the ERK signaling pathway to promote autophagy & [113] \\
\hline & $\mathrm{ApoE}^{-/-}$mice & $\begin{array}{c}\text { Enhance autophagy and downregulate } \mathrm{mTOR}, \mathrm{P} 53 \text { and P21 protein } \\
\text { expression levels to alleviate AS lesions and reduce lipid } \\
\text { accumulation and increase ratio of LC3 II/I }\end{array}$ & {$[83]$} \\
\hline \multirow{10}{*}{$\begin{array}{l}\text { Regulate lipid metabolism and reduce } \\
\text { the atherosclerotic plaque area }\end{array}$} & $\mathrm{ApoE}^{-/-}$mice & $\begin{array}{c}\text { Increase ABCA1 and LXR } \alpha \text { expression and downregulate PCSK9 } \\
\text { protein expression }\end{array}$ & [110] \\
\hline & Wistar rats & $\begin{array}{l}\text { Elevate activity of hepatic CYP7A1, LXR } \alpha \text {, and ABCG1 to promote } \\
\text { cholesterol-to-bile acid conversion and cholesterol efflux }\end{array}$ & {$[114]$} \\
\hline & C57BL/6J mice & $\begin{array}{c}\text { Upregulate LDLR and CYP7A1 gene expression to facilitate the } \\
\text { removal of cholesterol via fecal excretion }\end{array}$ & {$[115]$} \\
\hline & Wistar rats & $\begin{array}{c}\text { Promote conversion of cholesterol to bile acids and cholesterol efflux } \\
\text { by increasing hepatic CYP7A1 activity and hepatic LXR } \alpha \text {, ABCG1, } \\
\text { and LDLR protein expressions }\end{array}$ & {$[116]$} \\
\hline & $\mathrm{ApoE}^{-/-}$mice & $\begin{array}{c}\text { Elevate cholesterol accepting ability of HDL and increase ABCA1/G1 } \\
\text { expression levels of proteins related to RCT }\end{array}$ & [117] \\
\hline & $\begin{array}{l}\text { Sprague- } \\
\text { Dawley rats }\end{array}$ & $\begin{array}{c}\text { Influence gene and protein expression of SREBP1c and HMGR to } \\
\text { lower lipid }\end{array}$ & [118] \\
\hline & $\begin{array}{l}\text { Sprague- } \\
\text { Dawley rats }\end{array}$ & $\begin{array}{l}\text { Upregulate hepatic gene expression CYP7A1, LXR } \alpha, A B C A 1 \text {, and } \\
\text { ABCG1 to promote cholesterol efflux }\end{array}$ & [119] \\
\hline & Zucker rats & $\begin{array}{l}\text { Lower the level of HDL cholesterol and increase phosphorus level by } \\
\text { increasing the ratio of ASAT/ALAT activity induced by leptin }\end{array}$ & {$[56]$} \\
\hline & $\mathrm{ApoE}^{-/-}$mice & Regulate expressions of ABCA1, LXR $\alpha$, and PCSK9 & {$[26]$} \\
\hline & $\mathrm{ApoE}^{-/-}$mice & $\begin{array}{l}\text { Downregulate PCSK9 and CD } 36 \text { protein expression and upregulate } \\
\text { PPAR } \gamma, \mathrm{LXR} \alpha \text {, and ABCA1 protein expression levels in both the } \\
\text { aortic and liver tissues }\end{array}$ & {$[65]$} \\
\hline \multirow{4}{*}{ Alter the gut microbiota } & $\mathrm{ApoE}^{-/-}$mice & Regulate primary bile acid biosynthesis & [95] \\
\hline & C57BL/6J mice & $\begin{array}{c}\text { Improve composition and functionality of gut microbiome and } \\
\text { production of short chain fatty acids }\end{array}$ & {$[120]$} \\
\hline & Wistar rats & $\begin{array}{c}\text { Stimulate bacterial enzymatic activity and increase enzymatic activity } \\
\text { of the intestinal microbiota }\end{array}$ & {$[121]$} \\
\hline & Ldlr $^{-/-}$mice & $\begin{array}{l}\text { Reduce MDA, cholesterol, and LPC 18:1 and increase IL-6 and } \\
\text { coprostanol levels }\end{array}$ & {$[98]$} \\
\hline \multicolumn{4}{|c|}{ I } \\
\hline \multirow[t]{2}{*}{ Anti-inflammation } & $\begin{array}{l}\text { Healthy } \\
\text { nonsmokers }\end{array}$ & $\begin{array}{l}\text { Inhibit production of IL- } 1 \beta \text {, TNF- } \alpha \text {, IL- } 6 \text {, and IL- } 8 \text { in } \\
\text { Lipopolysaccharide-stimulated }\end{array}$ & {$[122]$} \\
\hline & CVD patients & Decrease transcriptional activity of NF-kB & {$[74]$} \\
\hline Endothelial protection & $\begin{array}{l}\text { CVD } \\
\text { individuals }\end{array}$ & Enhance NO bioavailability, possibly by stimulating eNOS activity & {$[123]$} \\
\hline
\end{tabular}

coronary heart disease $[105,106]$. Aspirin is one of the most widely used antiplatelet agents worldwide. Its use is associated with adverse events such as gastric bleeding, and whilst studies showed that decreasing aspirin doses reduces adverse event numbers without a reduction in antiplatelet efficacy, even lowdose aspirin treatment is associated with an increased bleeding risk [107]. As such, the pharmacological implications of the effects of the methylated metabolites of Qu with respect to the antiplatelet effects of aspirin are worthy of consideration. Apart from these actions, one more recent study showed that $\mathrm{Qu}$ processes an antiapoptotic effect in ischemic myocardial damage [108]. Altogether, these studies demonstrated that $\mathrm{Qu}$ may be a promising drug for the treatment and prevention of atherosclerosis in ASCVD. 
TABLE 2: Summary of the main effects of quercetin on antiatherosclerosis in vitro.

\begin{tabular}{|c|c|c|c|}
\hline Effect & Cell line & Target and mechanism & Reference \\
\hline \multicolumn{4}{|l|}{ Cells from animals } \\
\hline \multirow{5}{*}{ Anti-inflammation } & RAW264.7 cells & $\begin{array}{l}\text { Downregulate IL- } 1 \alpha \text {, IL-1 } \beta \text {, IL-2, IL-10, MCP-1, COX-2, MMP-1, SOCS3 induced } \\
\text { by LPS and suppress LPS-induced the phosphorylation of STAT3 }\end{array}$ & {$[18]$} \\
\hline & RAW264.7 cells & Suppress NF- $\kappa$ B and MAPK signaling in LPS-stimulated & {$[124]$} \\
\hline & VSMCs & $\begin{array}{c}\text { Suppress inflammation response via inactivating NF- } \kappa \mathrm{B} \text { and suppressing } \\
\text { proinflammatory gene expression }\end{array}$ & {$[78]$} \\
\hline & DCs & $\begin{array}{l}\text { Inhibit DC maturation via upregulation of Dabs and downregulate the Src/PI3K/ } \\
\text { Akt-NF- } \kappa \text { B-inflammatory pathways }\end{array}$ & {$[111]$} \\
\hline & RAW264.7 cells & Attenuate secretion of TNF- $\alpha$ or MCP-1 & [125] \\
\hline \multirow{3}{*}{$\begin{array}{l}\text { Endothelium } \\
\text { protection }\end{array}$} & RAW264.7 cells & Ameliorate overproduction of ROS induced by oxLDL & {$[18]$} \\
\hline & MPMs & $\begin{array}{l}\text { Inhibit ROS formation and block the vital step in activation of NADPH oxidase- } \\
\text { membrane translocation of p47phox }\end{array}$ & {$[16]$} \\
\hline & RAW264.7 cells & Protected sialic acid against $\mathrm{H}_{2} \mathrm{O}_{2}$-induced degradation & [125] \\
\hline \multirow{3}{*}{ Lipid lowering } & RAW264.7 cells & Ameliorate lipid deposition & {$[18]$} \\
\hline & Raw 264.7 cells & Improve the protein expression of $A B C G 1$ and $A B C A 1$ to promote cholesterol efflux & [125] \\
\hline & Raw 264.7 cells & $\begin{array}{l}\text { Upregulate the protein expression of ABCA1, ABCG1, and LXR } \alpha \text { and downregulate } \\
\text { the protein expression of PCSK9, P53, P21, and P16 }\end{array}$ & {$[126]$} \\
\hline \multirow{4}{*}{ Antiapoptosis } & NRK cells & Activate autophagy & [127] \\
\hline & RAW264.7 cells & $\begin{array}{c}\text { Promote autophagy by increasing expression of LC3-II/I and Beclin1 and block the } \\
\text { expression of MST1 induced by ox LDL }\end{array}$ & {$[86]$} \\
\hline & RAW264.7 cells & Activate the PI3K/AKT pathway & {$[78]$} \\
\hline & EPCs & Activate ERK and the ERK signaling pathway & {$[113]$} \\
\hline \multicolumn{4}{|l|}{ Cells from human } \\
\hline \multirow{7}{*}{ Anti-inflammation } & HUVECs & Attenuate caveolin-1 expression in endothelial cells & {$[128]$} \\
\hline & HUVECs & Reduce intracellular ROS and inhibit of NF- $\kappa$ B and AP- 1 activation & [129] \\
\hline & HUVECs & $\begin{array}{l}\text { Downregulate mRNA expression of MCP-1 and alleviate nuclear translocation of } \\
\text { NF- } \kappa \text { B p } 65 \text { subunit through attenuating the TLR-NF- } \kappa \text { B signaling pathway }\end{array}$ & [32] \\
\hline & PBMCs & $\begin{array}{c}\text { Suppress cytokine and TNF- } \alpha \text { release by modulating TLR-NF- } \kappa \text { B signaling pathway } \\
\text { and TLR-mediated MAPK pathway }\end{array}$ & {$[77]$} \\
\hline & HUVECs & Inhibit expression of proinflammatory factors and endothelin-1 & {$[130]$} \\
\hline & VSMCs & Inhibit TNF $\alpha$-mediated vascular inflammatory responses & {$[131]$} \\
\hline & HUVECs & $\begin{array}{l}\text { Inhibitory effect on MCP-1 as well as inflammatory cytokines including IL- } 1 \beta \text {, IL-6, } \\
\text { and TNF- } \alpha\end{array}$ & [132] \\
\hline \multirow{2}{*}{ Anti-apoptosis } & HaVSMCs & $\begin{array}{l}\text { Decrease relative expression levels of members of the mitochondrial apoptotic } \\
\text { pathway, including P53, puma and Noxa, caspase-3, and caspase-8 }\end{array}$ & [133] \\
\hline & EA.hy926 cells & $\begin{array}{l}\text { Regulate Akt/GSK3 } \beta \text { signaling pathway by increasing the expression of } \mathrm{p} \text {-Akt and } \mathrm{p} \text { - } \\
\text { GSK } 3 \beta\end{array}$ & {$[134]$} \\
\hline \multirow{2}{*}{ Lowering lipid } & $\begin{array}{l}\text { Human HepG2 cell } \\
\text { line }\end{array}$ & $\begin{array}{l}\text { Promote selective uptake of HDL-C by enhancing SR-BI expression through } \\
\text { stimulating the PPAR } \gamma / \mathrm{LXR} \alpha \text { pathway. }\end{array}$ & {$[61]$} \\
\hline & $\begin{array}{l}\text { THP-1 } \\
\text { macrophages }\end{array}$ & $\begin{array}{c}\text { Increase ABCA1 expression and cholesterol efflux through } \operatorname{LXR} \alpha \text { pathway to } \\
\text { promote RCT }\end{array}$ & {$[62]$} \\
\hline
\end{tabular}

Taken as in vitro and ex vitro together, the possible pathway of $\mathrm{Qu}$ on anti-atherosclerotic function is shown in Figure 3.

$\mathrm{Qu}$ can reduce the release of ROS and NOS to protect endothelial cells, improve the expression of ABCA1, ABCG1, and CYP7A1, promote cholesterol efflux in macrophages, downregulate the expressions of P53, P21, P16, and ERK, enhance autophagy to antiapoptosis, and inhibit MCP-1 as well as inflammatory cytokines including IL-1, IL2 , IL-1 $\beta$, IL-6, and TNF- $\alpha$ (Tables 1 and 2).

LPO, lipid peroxidation; ABCG1, ATP-binding cassette subfamily G member 1; LPC 18:1, lysophosphatidylcholine; IL-6, interleukin 6; SREBP-1c, sterol regulatory element binding protein-1c; HMGR, HMG-CoA reductase; ERK1/2, extracellular signal-regulated kinase (ERK) 1/2; ASAT/ ALAT, aspartate amino transferase/alanine amino transferase; CD36, cluster of differentiation 36; GSH, glutathione; CAT, catalase; Dab2, disabled 2; $\mathrm{Ldlr}^{-1-}$ mice, lowdensity lipoprotein receptor null mice; PON1, paraoxonase 1; CVD, coronary artery disease.

COX-2, cyclooxygenase-2; SOCS3, suppressor of cytokine signaling 3; STAT3, signal transducers and activators of transcription 3; Src, steroid receptor coactivator; VSMCs, vascular smooth muscle cells; DCs, dendritic cell; MPMs, mouse peritoneal macrophages, NRK, Normal rat kidney; EPCs, Endothelial progenitor cells; HUVECs, human umbilical vascular smooth muscle cells; PBMCs, Peripheral blood mononuclear cells; HaVSMCs, human aortic smooth muscle cells; EA.hy926 cells, an immortalized HUVEC line derived from fusion of HUVECs and lung adenocarcinoma cells; THP-1, human acute monocytic leukemia cell line. 


\section{Conclusion}

In the treatment of $\mathrm{ASCVD}, \mathrm{Qu}$ can reduce the formation of AS plaque through anti-inflammatory, antioxidation, regulation of lipid metabolism disorders, and other pharmacological effects, therefore reducing the incidence of ASCVD and improving the prognosis of ASCVD patients. In spite of medicine, surgery and intervention operation can improve the cardiac function; it still causes a considerable burden on families and caregivers and results in huge financial costs. Moreover, the high cost of surgery treatments and the failure of most conventional treatments have led the medical community to pursue cost-effective prevention and treatment. For ASCVD patients who are intolerant to surgery and cannot afford the high economic cost of treatment, it is a good choice to increase the Qu-rich low-fat diet in diet. Qu is rich in sources and has a wide range of pharmacological effects such as antitumor, antivirus, antiallergy, and antibacterial effects, which possess a broad prospect in application.

Although the new formulation of Qu has been developed and is partially used in clinics, due to its low bioavailability and low absorption rate, there are still many problems to be solved. Researchers need to further explore the pharmacological mechanism of Qu in human body so as to apply it to the prevention and treatment of clinical diseases better. It is also important to increase the water solubility and oral bioavailability of $\mathrm{Qu}$ in the future research. In the further study of phytochemistry, the research field of medicinal activity of Qu should be highlighted for its multiple biological characteristics.

\section{Conflicts of Interest}

The authors declare that they have no conflicts of interest regarding the publication of this paper.

\section{Authors' Contributions}

Jingui Xue and Qian Deng contributed to the topic conception, manuscript revision, and decision to submit for publication. Xin Chen, Xiaoxue Li, and YanTing Fang participated in the collection of documentation.

\section{Acknowledgments}

The authors acknowledge the financial support provided by the National Natural Science Foundation of China (81774088 and 81703743).

\section{References}

[1] R. Ross, "Atherosclerosis-an inflammtory diease," The New England Journal of Medicine, vol. 340, p. 12, 1999.

[2] A. Tuttolomondo, D. Di Raimondo, and R. Pecoraro, "Atherosclerosis as an inflammatory disease," Current Pharmaceutical Design, vol. 18, p. 22, 2012.

[3] H. Shengtao, R. Gao, L. Liu et al., "Summary of China cardiovascular disease report 2018," Chinese Circulation Journal, vol. 34, no. 3, pp. 209-220, 2019.
[4] E. S. Ford, V. L. Roger, S. M. Dunlay, A. S. Go, and W. D. Rosamond, "Challenges of ascertaining national trends in the incidence of coronary heart disease in the United States," Journal of the American Heart Association, vol. 3, no. 6, Article ID e001097, 2014.

[5] S. C. Bergheanu, M. C. Bodde, and J. W. Jukema, "Pathophysiology and treatment of atherosclerosis," Netherlands Heart Journal, vol. 25, no. 4, pp. 231-242, 2017.

[6] A. L. Catapano, I. Graham, G. De Backer et al., "2016 ESC/ EAS guidelines for the management of dyslipidaemias," Atherosclerosis, vol. 253, pp. 281-344, 2016.

[7] S. J. L. van der Tuin, S. Kühnast, J. F. P. Berbée et al., "Anacetrapib reduces (V) LDL cholesterol by inhibition of CETP activity and reduction of plasma PCSK9," Journal of Lipid Research, vol. 56, no. 11, pp. 2085-2093, 2015.

[8] K. Tsujita, S. Sugiyama, H. Sumida et al., "Impact of dual lipid-lowering strategy with ezetimibe and atorvastatin on coronary plaque regression in patients with percutaneous coronary intervention," Journal of the American College of Cardiology, vol. 66, no. 5, pp. 495-507, 2015.

[9] H. J. Bae, K. Sowndhararajan, H.-B. Park et al., "Danshensu attenuates scopolamine and amyloid- $\beta$-induced cognitive impairments through the activation of PKA-CREB signaling in mice," Neurochemistry International, vol. 131, Article ID 104537, 2019.

[10] F. Li, F. Lang, H. Zhang et al., "Apigenin alleviates endotoxin-induced myocardial toxicity by modulating inflammation, oxidative stress, and autophagy," Oxidative Medicine and Cellular Longevity, vol. 2017, Article ID 2302896, 10 pages, 2017.

[11] R. W. Zhang, "Artemisinin (Qinghaosu), nobel prize, antimalaria, and beyond," Chinese Journal of Natural Medicines, vol. 14, pp. 1-2, 2016.

[12] S.-H. Tu, L.-C. Chen, and Y.-S. Ho, "An apple a day to prevent cancer formation: reducing cancer risk with flavonoids," Journal of Food and Drug Analysis, vol. 25, no. 1, pp. 119-124, 2017.

[13] N. Yahfoufi, N. Alsadi, M. Jambi, and C. Matar, "The immunomodulatory and anti-inflammatory role of polyphenols," Nutrients, vol. 10, no. 11, 2018.

[14] T. Tsuda, "Recent progress in anti-obesity and anti-diabetes effect of berries," Antioxidants, vol. 5, no. 2, p. 13, 2016.

[15] Y. Guan, H.-j. Shen, J. Shen et al., "Anti-allergic activities of 5,7-dimethoxy-3,4'-dihydroxyflavone via inhalation in rat allergic models," European Journal of Pharmacology, vol. 848, pp. 55-61, 2019.

[16] L. Xiao, L. Liu, X. Guo et al., "Quercetin attenuates high fat diet-induced atherosclerosis in apolipoprotein E knockout mice: a critical role of NADPH oxidase," Food and Chemical Toxicology, vol. 105, pp. 22-33, 2017.

[17] V. Calabró, M. C. Litterio, C. G. Fraga, M. Galleano, and B. Piotrkowski, "Effects of quercetin on heart nitric oxide metabolism in 1-NAME treated rats," Archives of Biochemistry and Biophysics, vol. 647, pp. 47-53, 2018.

[18] F. Xue, X. Nie, J. Shi et al., "Quercetin inhibits LPS-induced inflammation and ox-LDL-induced lipid deposition," Frontiers in Pharmacology, vol. 8, p. 40, 2017.

[19] S. Rusznyak and A. Szent-Györgyi, "Vitamin P: flavonols as vitamins," Nature, vol. 138, no. 3479, p. 27, 1936.

[20] A. V. Anand David, R. Arulmoli, and S. Parasuraman, "Overviews of biological importance of quercetin: a bioactive flavonoid," Pharmacognosy Reviews, vol. 10, no. 20, pp. 8489, 2016.

[21] E. N. Frankel, J. B. German, J. E. Kinsella, E. Parks, and J. Kanner, "Inhibition of oxidation of human low-density 
lipoprotein by phenolic substances in red wine," The Lancet, vol. 341, no. 8843, pp. 454-457, 1993.

[22] P. M. Kris-Etherton and C. L. Keen, "Evidence that the antioxidant flavonoids in tea and cocoa are beneficial for cardiovascular health," Current Opinion in Lipidology, vol. 13, no. 1, pp. 41-49, 2002.

[23] L. Roubalová, K. Purchartová, B. Papoušková et al., "Sulfation modulates the cell uptake, antiradical activity and biological effects of flavonoids in vitro: an examination of quercetin, isoquercitrin and taxifolin," Bioorganic \& $\mathrm{Me}$ dicinal Chemistry, vol. 23, no. 17, pp. 5402-5409, 2015.

[24] F. Ververidis, E. Trantas, C. Douglas, G. Vollmer, G. Kretzschmar, and N. Panopoulos, "Biotechnology of flavonoids and other phenylpropanoid-derived natural products. Part I: chemical diversity, impacts on plant biology and human health," Biotechnology Journal, vol. 2, no. 10, pp. 1214-1234, 2007.

[25] J.-S. Nam, A. Sharma, L. Nguyen, C. Chakraborty, G. Sharma, and S.-S. Lee, "Application of bioactive quercetin in oncotherapy: from nutrition to nanomedicine," Molecules, vol. 21, no. 1, p. 108, 2016.

[26] L. J. Li, G. W. Li, and Y. Xie, "Regulatory effects of glabridin and quercetin on energy metabolism of breast cancer cells," Zhongguo Zhong Yao Za Zhi, vol. 44, no. 17, pp. 3786-3791, 2019.

[27] G. T. Kim, S. H. Lee, J. I. Kim, and Y. M. Kim, "Quercetin regulates the sestrin 2-AMPK-p38 MAPK signaling pathway and induces apoptosis by increasing the generation of intracellular ROS in a p53-independent manner," International Journal of Molecular Medicine, vol. 33, no. 4, pp. 863-869, 2014.

[28] J.-H. Chang, S.-L. Lai, W.-S. Chen et al., "Quercetin suppresses the metastatic ability of lung cancer through inhibiting Snail-dependent Akt activation and Snail-independent ADAM9 expression pathways," Biochimica et Biophysica Acta (BBA)-Molecular Cell Research, vol. 1864, no. 10, pp. 1746-1758, 2017.

[29] C. C. Nwaeburu, A. Abukiwan, Z. Zhao, and I. Herr, "Quercetin-induced miR-200b-3p regulates the mode of selfrenewing divisions in pancreatic cancer," Molecular Cancer, vol. 16, no. 1, p. 23, 2017.

[30] M. Kosari-Nasab, G. Shokouhi, A. Ghorbanihaghjo, M. Mesgari-Abbasi, and A.-A. Salari, "Quercetin mitigates anxiety-like behavior and normalizes hypothalamus-pituitary-adrenal axis function in a mouse model of mild traumatic brain injury," Behavioural Pharmacology, vol. 30, no. 2-3, pp. 282-289, 2019.

[31] H. M. Eid and P. S. Haddad, "The antidiabetic potential of quercetin: underlying mechanisms," Current Medicinal Chemistry, vol. 24, no. 4, pp. 355-364, 2017.

[32] S. Bhaskar, P. R. Sudhakaran, and A. Helen, "Quercetin attenuates atherosclerotic inflammation and adhesion molecule expression by modulating TLR-NF- $\kappa \mathrm{B}$ signaling pathway," Cellular Immunology, vol. 310, pp. 131-140, 2016.

[33] P. Dhiman, N. Malik, E. Sobarzo-Sánchez, E. Uriarte, and A. Khatkar, "Quercetin and related chromenone derivatives as monoamine oxidase inhibitors: targeting neurological and mental disorders," Molecules, vol. 24, no. 3, p. 418, 2019.

[34] K. M. Doersch and M. K. Newell-Rogers, "The impact of quercetin on wound healing relates to changes in $\alpha \mathrm{V}$ and $\beta 1$ integrin expression," Experimental Biology and Medicine, vol. 242, no. 14, pp. 1424-1431, 2017.
[35] X. Cai, Z. Fang, J. Dou, A. Yu, and G. Zhai, "Bioavailability of quercetin: problems and promises," Current Medicinal Chemistry, vol. 20, pp. 2572-2582, 2013.

[36] M. Reinboth, S. Wolffram, G. Abraham, F. R. Ungemach, and R. Cermak, "Oral bioavailability of quercetin from different quercetin glycosides in dogs," British Journal of Nutrition, vol. 104, no. 2, pp. 198-203, 2010.

[37] A. K. Jain, K. Thanki, and S. Jain, "Co-encapsulation of tamoxifen and quercetin in polymeric nanoparticles: implications on oral bioavailability, antitumor efficacy, and drug-induced toxicity," Molecular Pharmaceutics, vol. 10, no. 9, pp. 3459-3474, 2013.

[38] X. Lv, T. Liu, H. Ma et al., "Preparation of essential oil-based microemulsions for improving the solubility, $\mathrm{pH}$ stability, photostability, and skin permeation of quercetin," AAPS PharmSciTech, vol. 18, no. 8, pp. 3097-3104, 2017.

[39] N. Sermkaew and T. Plyduang, "Self-microemulsifying drug delivery systems of Moringa oleifera extract for enhanced dissolution of kaempferol and quercetin," Acta Pharmaceutica, vol. 70, no. 1, pp. 77-88, 2020.

[40] Li Miao, L. Wang, and B. Chang, "Research progress in the mechanism of vascular endothelial cell dysfunction," Chinese Journal of Arteriosclerosis, vol. 27, no. 8, pp. 730-736, 2019.

[41] D. H. Endemann and E. L. Schiffrin, "Endothelial dysfunction," Journal of the American Society of Nephrology, vol. 15, no. 8, pp. 1983-1992, 2004.

[42] Y. Chao, "Effects of quercetin on vascular endothelial cell growth and NO production," Journal of Dalian University, vol. 31, no. 6, pp. 84-86, 2010.

[43] S. Tribolo, F. Lodi, C. Connor et al., "Comparative effects of quercetin and its predominant human metabolites on adhesion molecule expression in activated human vascular endothelial cells," Atherosclerosis, vol. 197, no. 1, pp. 50-56, 2008.

[44] L. Yi, X. Jin, C.-Y. Chen et al., "Chemical structures of 4-oxoflavonoids in relation to inhibition of oxidized low-density lipoprotein (LDL)-induced vascular endothelial dysfunction," International Journal of Molecular Sciences, vol. 12, no. 9, pp. 5471-5489, 2011.

[45] H. Xi, W. Zhang, L. Zhao, and J. Hu, "Protective effect of quercetin on endothelial cells injured by excessive no," in Proceedings of the 2013 Zhejiang Annual Conference on Electrophysiology and Pacing, Shaoxing, China, 2013.

[46] R. Ross and Russell, "The pathogenesis of atherosclerosis," Mechanisms of Ageing and Development, vol. 9, no. 5-6, pp. 435-440, 1979 .

[47] L. Yingying, S. Chen, and D. Wang, "Research progress of oxidative stress on endothelial cell injury in atherosclerosis," Medical Recapitulate, vol. 21, no. 5, pp. 772-775, 2015.

[48] C. L. L. Saw, Y. Guo, A. Y. Yang et al., "The berry constituents quercetin, kaempferol, and pterostilbene synergistically attenuate reactive oxygen species: involvement of the Nrf2ARE signaling pathway," Food and Chemical Toxicology, vol. 72, pp. 303-311, 2014.

[49] J. S. Stamler, J. A. Osborne, O. Jaraki et al., "Adverse vascular effects of homocysteine are modulated by endotheliumderived relaxing factor and related oxides of nitrogen," Journal of Clinical Investigation, vol. 91, no. 1, pp. 308-318, 1993.

[50] N. Çelik, A. Vurmaz, and A. Kahraman, "Protective effect of quercetin on homocysteine-induced oxidative stress," $\mathrm{Nu}$ trition, vol. 33, pp. 291-296, 2017.

[51] E. O. Farombi and O. O. Onyema, "Monosodium glutamateinduced oxidative damage and genotoxicity in the rat: 
modulatory role of vitamin C, vitamin E and quercetin," Human \& Experimental Toxicology, vol. 25, no. 5, pp. 251259, 2006.

[52] C. H. Park, M. Y. Kim, D.-E. Sok, J. H. Kim, J. H. Lee, and M. R. Kim, "Butterbur (Petasites japonicus max.) extract improves lipid profiles and antioxidant activities in monosodium L-glutamate-challenged mice," Journal of Medicinal Food, vol. 13, no. 5, pp. 1216-1223, 2010.

[53] F. R. F. Seiva, L. G. A. Chuffa, C. P. Braga, J. P. A. Amorim, and A. A. H. Fernandes, "Quercetin ameliorates glucose and lipid metabolism and improves antioxidant status in postnatally monosodium glutamate-induced metabolic alterations," Food and Chemical Toxicology, vol. 50, no. 10, pp. 3556-3561, 2012.

[54] V. V. Padma, G. Lalitha, N. P. Shirony, and R. Baskaran, "Effect of quercetin against lindane induced alterations in the serum and hepatic tissue lipids in wistar rats," Asian Pacific Journal of Tropical Biomedicine, vol. 2, no. 11, pp. 910-915, 2012.

[55] V. R. Punithavathi and P. S. M. Prince, "Combined effects of quercetin and $\alpha$-tocopherol on lipids and glycoprotein components in isoproterenol induced myocardial infarcted Wistar rats," Chemico-Biological Interactions, vol. 181, no. 3, pp. 322-327, 2009.

[56] Y. Liu, Y. Gu, Y. Shen et al., "Association between serum leptin level and calcific aortic valve disease," Journal of the American Heart Association, vol. 8, no. 19, Article ID e012495, 2019.

[57] K. V. Mzhelskaya, V. A. Shipelin, A. A. Shumakova et al., "Effects of quercetin on the neuromotor function and behavioral responses of Wistar and Zucker rats fed a high-fat and high-carbohydrate diet," Behavioural Brain Research, vol. 378, Article ID 112270, 2020.

[58] B. Bonamassa and A. Moschetta, "Atherosclerosis: lessons from LXR and the intestine," Trends in Endocrinology \& Metabolism, vol. 24, no. 3, pp. 120-128, 2013.

[59] M. F. Linton, H. Tao, E. F. Linton, and P. G. Yancey, "SR-BI: a multifunctional receptor in cholesterol homeostasis and atherosclerosis," Trends in Endocrinology \& Metabolism, vol. 28, no. 6, pp. 461-472, 2017.

[60] L. Xueyan, Y. Yang, and J. Chen, "Research progress of Chinese herbal medicine against macrophage foam," Pharmaceutical and Clinical Research, vol. 25, no. 5, pp. 431-434, 2017.

[61] K. Ren, T. Jiang, and G.-J. Zhao, "Quercetin induces the selective uptake of HDL-cholesterol via promoting SR-BI expression and the activation of the PPAR $\gamma / \mathrm{LXR} \alpha$ pathway," Food \& Function, vol. 9, no. 1, pp. 624-635, 2018.

[62] Y. Lu and Y. P. Jia, "Quercetin upregulates ABCA1 expression through liver $\mathrm{X}$ receptor alpha signaling pathway in THP-1 macrophages," European Review for Medical and Pharmacological Sciences, vol. 20, no. 18, pp. 3945-3952, 2016.

[63] L. Sun, E. Li, F. Wang et al., "Quercetin increases macrophage cholesterol efflux to inhibit foam cell formation through activating PPAR $\gamma$-ABCA1 pathway," International Journal of Clinical and Experimental Pathology, vol. 8, no. 9, pp. 10854-10860, 2015.

[64] Y.-C. Chang, T.-S. Lee, and A.-N. Chiang, "Quercetin enhances ABCA1 expression and cholesterol efflux through a p38-dependent pathway in macrophages," Journal of Lipid Research, vol. 53, no. 9, pp. 1840-1850, 2012.

[65] Q. Jia, H. Cao, D. Shen et al., "Quercetin protects against atherosclerosis by regulating the expression of PCSK9,
CD36, PPAR $\gamma, \mathrm{LXR} \alpha$ and ABCA1," International Journal of Molecular Medicine, vol. 44, no. 3, pp. 893-902, 2019.

[66] Y. Zhang, Y. Si, L. Zhai et al., "Celastrus orbiculatus thunb. Reduces lipid accumulation by promoting reverse cholesterol transport in hyperlipidemic mice," Lipids, vol. 51, no. 6, pp. 677-692, 2016b.

[67] A. N. Orekhov, "The role of modified and dysfunctional lipoproteins in atherogenesis," Current Medicinal Chemistry, vol. 26, no. 9, pp. 1509-1511, 2019.

[68] M.-Y. Yang, C.-N. Huang, K.-C. Chan, Y.-S. Yang, C.-H. Peng, and C.-J. Wang, "Mulberry leaf polyphenols possess antiatherogenesis effect via inhibiting LDL oxidation and foam cell formation," Journal of Agricultural and Food Chemistry, vol. 59, no. 5, pp. 1985-1995, 2011.

[69] O. J. Lara-Guzman, J. H. Tabares-Guevara, Y. M. LeonVarela et al., "Proatherogenic macrophage activities are targeted by the flavonoid quercetin," Journal of Pharmacology and Experimental Therapeutics, vol. 343, no. 2, pp. 296-306, 2012.

[70] M. M. Kavurma, K. J. Rayner, and D. Karunakaran, "The walking dead," Current Opinion in Lipidology, vol. 28, no. 2, pp. 91-98, 2017.

[71] K. J. Moore, F. J. Sheedy, and E. A. Fisher, "Macrophages in atherosclerosis: a dynamic balance," Nature Reviews Immunology, vol. 13, no. 10, pp. 709-721, 2013.

[72] A. M. Manning, F. P. Bell, C. L. Rosenbloom et al., "NFkappa B is activated during acute inflammation in vivo in association with elevated endothelial cell adhesion molecule gene expression and leukocyte recruitment," Journal of Inflammation, vol. 45, no. 4, pp. 283-296, 1995.

[73] X.-P. Zhang, L. Zhang, L. J. Chen et al., "Influence of dexamethasone on inflammatory mediators and NF- $\kappa \mathrm{B}$ expression in multiple organs of rats with severe acute pancreatitis," World Journal of Gastroenterology, vol. 13, no. 4, pp. 548-556, 2007.

[74] N. Chekalina, Y. Burmak, Y. Petrov et al., "Quercetin reduces the transcriptional activity of NF- $\kappa$ B in stable coronary artery disease," Indian Heart Journal, vol. 70, no. 5, pp. 593-597, 2018.

[75] P.-Y. Chao, Y.-P. Huang, and W.-B. Hsieh, "Inhibitive effect of purple sweet potato leaf extract and its components on cell adhesion and inflammatory response in human aortic endothelial cells," Cell Adhesion \& Migration, vol. 7, no. 2, pp. 237-245, 2013.

[76] T. D. Troutman, J. F. Bazan, and C. Pasare, "Toll-like receptors, signaling adapters and regulation of the pro-inflammatory response by PI3K," Cell Cycle, vol. 11, no. 19, pp. 3559-3567, 2012.

[77] S. Bhaskar and A. Helen, "Quercetin modulates toll-like receptor-mediated protein kinase signaling pathways in oxLDL-challenged human PBMCs and regulates TLR-activated atherosclerotic inflammation in hypercholesterolemic rats," Molecular and Cellular Biochemistry, vol. 423, no. 1-2, pp. 53-65, 2016.

[78] X.-L. Lu, C.-H. Zhao, X.-L. Yao, and H. Zhang, "Quercetin attenuates high fructose feeding-induced atherosclerosis by suppressing inflammation and apoptosis via ROS-regulated PI3K/AKT signaling pathway," Biomedicine \& Pharmacotherapy, vol. 85, pp. 658-671, 2017.

[79] A. Pietersma, B. C. Tilly, M. Gaestel et al., "p38 mitogen activated protein kinase regulates endothelial VCAM-1 expression at the post-transcriptional level," Biochemical and Biophysical Research Communications, vol. 230, no. 1, pp. 44-48, 1997. 
[80] M. Goebeler, K. Kilian, R. Gillitzer et al., "The MKK6/p38 stress kinase cascade is critical for tumor necrosis factorinduced expression of monocyte-chemoattractant protein-1 in endothelial cells," Blood, vol. 93, no. 3, pp. 857-865, 1999.

[81] C. Li, W.-J. Zhang, and B. Frei, "Quercetin inhibits LPSinduced adhesion molecule expression and oxidant production in human aortic endothelial cells by p38-mediated Nrf2 activation and antioxidant enzyme induction," Redox Biology, vol. 9, pp. 104-113, 2016.

[82] L. Qiao, X. Zhang, M. Liu et al., "Corrigendum: ginsenoside $\mathrm{Rb} 1$ enhances atherosclerotic plaque stability by improving autophagy and lipid metabolism in macrophage foam cells," Frontiers in Pharmacology, vol. 8, p. 964, 2017.

[83] H. Cao, Q. Jia, D. Shen, L. Yan, C. Chen, and S. Xing, "Quercetin has a protective effect on atherosclerosis via enhancement of autophagy in $\mathrm{ApoE}^{-/-}$mice," Experimental and Therapeutic Medicine, vol. 18, no. 4, pp. 2451-2458, 2019.

[84] M. Ashrafizadeh, Z. Ahmadi, T. Farkhondeh, and S. Samarghandian, "Autophagy as a molecular target of quercetin underlying its protective effects in human diseases," Archives of Physiology and Biochemistry, pp. 1-9, 2019.

[85] Y. Ma, Z. Huang, Z. Zhou et al., "A novel antioxidant MitoTempol inhibits ox-LDL-induced foam cell formation through restoration of autophagy flux," Free Radical Biology and Medicine, vol. 129, pp. 463-472, 2018.

[86] H. Cao, Q. Jia, L. Yan, C. Chen, S. Xing, and D. Shen, "Quercetin suppresses the progression of atherosclerosis by regulating MST1-mediated autophagy in ox-LDL-induced RAW264.7 macrophage foam cells," International Journal of Molecular Sciences, vol. 20, no. 23, p. 6093, 2019.

[87] A. Ardestani, F. Paroni, Z. Azizi et al., "MST1 is a key regulator of beta cell apoptosis and dysfunction in diabetes," Nature Medicine, vol. 20, no. 4, pp. 385-397, 2014.

[88] J. Lin, L. Zhang, M. Zhang et al., "Mst1 inhibits CMECs autophagy and participates in the development of diabetic coronary microvascular dysfunction," Scientific Reports, vol. 6, no. 1, p. 34199, 2016.

[89] J. Bu and Z. Wang, "Cross-talk between gut microbiota and heart via the routes of metabolite and immunity," Gastroenterology Research and Practice, vol. 2018, Article ID 6458094, 8 pages, 2018.

[90] S. Lim, M.-R. Taskinen, and J. Borén, "Crosstalk between nonalcoholic fatty liver disease and cardiometabolic syndrome," Obesity Reviews, vol. 20, no. 4, pp. 599-611, 2019.

[91] J. Ma and H. Li, "The role of gut microbiota in atherosclerosis and hypertension," Frontiers in Pharmacology, vol. 9, p. 1082, 2018.

[92] S. C. Gominak, "Vitamin D deficiency changes the intestinal microbiome reducing $\mathrm{B}$ vitamin production in the gut. The resulting lack of pantothenic acid adversely affects the immune system, producing a "pro-inflammatory" state associated with atherosclerosis and autoimmunity," Medical Hypotheses, vol. 94, pp. 103-107, 2016.

[93] E. Org, M. Mehrabian, and A. J. Lusis, "Unraveling the environmental and genetic interactions in atherosclerosis: central role of the gut microbiota," Atherosclerosis, vol. 241, no. 2, pp. 387-399, 2015.

[94] W. T. Barrington and A. J. Lusis, "Association between the gut microbiome and atherosclerosis," Nature Reviews Cardiology, vol. 14, no. 12, pp. 699-700, 2017.

[95] D.-N. Wu, L. Guan, Y.-X. Jiang et al., "Microbiome and metabonomics study of quercetin for the treatment of atherosclerosis," Cardiovascular Diagnosis and Therapy, vol. 9, no. 6, pp. 545-560, 2019.
[96] R. Li, J. Yang, A. Saffari et al., "Ambient ultrafine particle ingestion alters gut microbiota in association with increased atherogenic lipid metabolites," Scientific Reports, vol. 7, no. 1, p. 42906, 2017.

[97] X. Liu, J. Sheng, and R. Curtiss III, "Fatty acid production in genetically modified cyanobacteria," Proceedings of the $\mathrm{Na}$ tional Academy of Sciences, vol. 108, no. 17, pp. 6899-6904, 2011.

[98] J. Nie, L. Zhang, G. Zhao, and X. Du, "Quercetin reduces atherosclerotic lesions by altering the gut microbiota and reducing atherogenic lipid metabolites," Journal of Applied Microbiology, vol. 127, no. 6, pp. 1824-1834, 2019.

[99] N. Panth, K. R. Paudel, and K. Parajuli, "Reactive oxygen species: a key hallmark of cardiovascular disease," Advances in Medicine, vol. 2016, Article ID 9152732, 12 pages, 2016.

[100] O. A. Azizova, A. V. Aseichev, A. P. Piryazev, E. V. Roitman, and O. N. Shcheglovitova, "Effects of oxidized fibrinogen on the functions of blood cells, blood clotting, and rheology," Bulletin of Experimental Biology and Medicine, vol. 144, no. 3, pp. 397-407, 2007.

[101] A. Parvin, P. Yaghmaei, M. Noureddini, S. A. Haeri Roohani, and S. Aminzadeh, "Comparative effects of quercetin and hydroalcoholic extract of Otostegia persica boiss with atorvastatin on atherosclerosis complication in male wistar rats," Food Science \& Nutrition, vol. 7, no. 9, pp. 2875-2887, 2019.

[102] K.-H. Lee, E. Park, H.-J. Lee et al., "Effects of daily quercetinrich supplementation on cardiometabolic risks in male smokers," Nutrition Research and Practice, vol. 5, no. 1, pp. 28-33, 2011.

[103] W. J. Oh, M. Endale, S.-C. Park, J. Y. Cho, and M. H. Rhee, "Dual roles of quercetin in platelets: phosphoinositide-3kinase and MAP kinases inhibition, and cAMP-dependent vasodilator-stimulated phosphoprotein stimulation," Evidence-Based Complementary and Alternative Medicine, vol. 2012, Article ID 485262, 10 pages, 2012.

[104] A. R. Stainer, P. Sasikumar, A. P. Bye et al., "The metabolites of the dietary flavonoid quercetin possess potent antithrombotic activity, and interact with aspirin to enhance antiplatelet effects," TH Open, vol. 3, no. 3, pp. e244-e258, 2019.

[105] J. Stewart, G. Manmathan, and P. Wilkinson, "Primary prevention of cardiovascular disease: a review of contemporary guidance and literature," JRSM Cardiovascular Disease, vol. 6, 2017.

[106] P. O. Vandvik, A. M. Lincoff, J. M. Gore et al., "Primary and secondary prevention of cardiovascular disease," Chest, vol. 141, no. 2, pp. e637S-e668S, 2012.

[107] L. A. García Rodríguez, M. Martín-Pérez, C. H. Hennekens, P. M. Rothwell, and A. Lanas, "Bleeding risk with long-term low-dose aspirin: a systematic review of observational studies," PLoS One, vol. 11, no. 8, Article ID e0160046, 2016.

[108] B. Li, M. Yang, J. W. Liu, and G. T. Yin, "Protective mechanism of quercetin on acute myocardial infarction in rats," Genetics and Molecular Research, vol. 15, no. 1, p. 15017117, 2016.

[109] A. R. Vanani, M. Mahdavinia, M. Shirani, S. Alizadeh, M. A. Dehghani, and M. Amin Dehghani, "Protective effects of quercetin against oxidative stress induced by bisphenol-A in rat cardiac mitochondria," Environmental Science and Pollution Research, vol. 27, no. 13, pp. 15093-15102, 2020.

[110] S.-s. Li, H. Cao, D.-z. Shen et al., "Effect of quercetin on atherosclerosis based on expressions of ABCA1, LXR- $\alpha$ and 
PCSK9 in ApoE ${ }^{-1-}$ mice," Chinese Journal of Integrative Medicine, vol. 26, no. 2, pp. 114-121, 2020.

[111] W. Ling, W. Lin, W. Wang, and D. Wang, "Quercetin protects against atherosclerosis by inhibiting dendritic cell activation," Annals of Nutrition and Metabolism, vol. 71, pp. 186-187, 2017.

[112] D. Atrahimovich, A. O. Samson, A. Khattib, J. Vaya, and S. Khatib, "Punicalagin decreases serum glucose levels and increases PON1 activity and HDL anti-inflammatory values in balb/c mice fed a high-fat diet," Oxidative Medicine and Cellular Longevity, vol. 2018, Article ID 2673076, 8 pages, 2018.

[113] K. Zhi, M. Li, J. Bai et al., "Quercitrin treatment protects endothelial progenitor cells from oxidative damage via inducing autophagy through extracellular signal-regulated kinase," Angiogenesis, vol. 19, no. 3, pp. 311-324, 2016.

[114] M. Zhang, Z. Xie, W. Gao, L. Pu, J. Wei, and C. Guo, "Quercetin regulates hepatic cholesterol metabolism by promoting cholesterol-to-bile acid conversion and cholesterol efflux in rats," Nutrition Research, vol. 36, no. 3, pp. 271-279, 2016.

[115] H.-J. Kang, P. B. T. Pichiah, R. V. Abinaya, H.-S. Sohn, and Y.-S. Cha, "Hypocholesterolemic effect of quercetin-rich onion peel extract in C57BL/6J mice fed with high cholesterol diet," Food Science and Biotechnology, vol. 25, no. 3, pp. 855-860, 2016.

[116] B. C. Variya, A. K. Bakrania, and S. S. Patel, "Emblica officinalis (Amla): a review for its phytochemistry, ethnomedicinal uses and medicinal potentials with respect to molecular mechanisms," Pharmacological Research, vol. 111, pp. 180-200, 2016.

[117] Y. Cui, P. Hou, F. Li et al., "Quercetin improves macrophage reverse cholesterol transport in apolipoprotein E-deficient mice fed a high-fat diet," Lipids in Health and Disease, vol. 16, no. 1, p. 9, 2017.

[118] N. Somparn, S. Saenthaweeuk, J. Naowaboot, A. Thaeomor, and V. Kukongviriyapan, "Effect of lemongrass water extract supplementation on atherogenic index and antioxidant status in rats," Acta Pharmaceutica, vol. 68, no. 2, pp. 185197, 2018.

[119] H.-Y. Son, M.-S. Lee, E. Chang et al., "Formulation and characterization of quercetin-loaded oil in water nanoemulsion and evaluation of hypocholesterolemic activity in rats," Nutrients, vol. 11, no. 2, p. 244, 2019.

[120] S. Tan, J. A. Caparros-Martin, V. B. Matthews et al., "Isoquercetin and inulin synergistically modulate the gut microbiome to prevent development of the metabolic syndrome in mice fed a high fat diet," Scientific Reports, vol. 8, no. 1, 2018.

[121] K. Grzelak-Blaszczyk, J. Milala, M. Kosmala et al., "Onion quercetin monoglycosides alter microbial activity and increase antioxidant capacity," Journal of Nutritional Biochemistry, vol. 56, pp. 81-88, 2018.

[122] C. Zaragozá, L. Villaescusa, J. Monserrat, F. Zaragozá, and M. Álvarez-Mon, "Potential therapeutic anti-inflammatory and immunomodulatory effects of dihydroflavones, flavones, and flavonols," Molecules, vol. 25, no. 4, p. 1017, 2020.

[123] B. R. Bhavnani, A. Cecutti, A. Gerulath, A. C. Woolever, and M. Berco, "Comparison of the antioxidant effects of equine estrogens, red wine components, vitamin $\mathrm{E}$, and probucol on low-density lipoprotein oxidation in postmenopausal women," Menopause, vol. 25, no. 11, pp. 1214-1223, 2018.

[124] T.-L. Si, Q. Liu, Y.-F. Ren et al., "Enhanced anti-inflammatory effects of DHA and quercetin in lipopolysaccharide- induced RAW264.7 macrophages by inhibiting NF- $\kappa$ B and MAPK activation," Molecular Medicine Reports, vol. 14, no. 1, pp. 499-508, 2016.

[125] H. Tian, Q. Liu, S. Qin et al., "Synthesis and cardiovascular protective effects of quercetin 7-O-sialic acid," Journal of Cellular and Molecular Medicine, vol. 21, no. 1, pp. 107-120, 2017.

[126] S. Li, H. Cao, D. Shen, Q. Jia, C. Chen, and S. Xing, "Quercetin protects against ox-LDL-induced injury via regulation of ABCAl, LXR- $\alpha$ and PCSK9 in RAW264.7 macrophages," Molecular Medicine Reports, vol. 18, no. 1, pp. 799-806, 2018.

[127] X. Zhang, D. An, and L. Guo, "Preliminary screening of active components in regulating autophagy in Ziziphora clinopodioide Lam," Pakistan Journal of Pharmaceutical Sciences, vol. 32, pp. 2611-2615, 2019.

[128] C. Kamada, R. Mukai, A. Kondo, S. Sato, and J. Terao, "Effect of quercetin and its metabolite on caveolin-1 expression induced by oxidized LDL and lysophosphatidylcholine in endothelial cells," Journal of Clinical Biochemistry and $\mathrm{Nu}$ trition, vol. 58, no. 3, pp. 193-201, 2016.

[129] N. Calabriso, E. Scoditti, M. Massaro et al., "Multiple antiinflammatory and anti-atherosclerotic properties of red wine polyphenolic extracts: differential role of hydroxycinnamic acids, flavonols and stilbenes on endothelial inflammatory gene expression," European Journal of Nutrition, vol. 55, no. 2, pp. 477-489, 2016.

[130] X. Cai, L. Bao, Y. Ding, X. Dai, Z. Zhang, and Y. Li, "Quercetin alleviates cell apoptosis and inflammation via the ER stress pathway in vascular endothelial cells cultured in high concentrations of glucosamine," Molecular Medicine Reports, vol. 15, no. 2, pp. 825-832, 2017.

[131] S.-A. Jang, D. W. Park, E. H. Sohn, S. R. Lee, and S. C. Kang, "Hyperoside suppresses tumor necrosis factor $\alpha$-mediated vascular inflammatory responses by downregulating mitogen-activated protein kinases and nuclear factor- $\kappa \mathrm{B}$ signaling," Chemico-Biological Interactions, vol. 294, pp. 48-55, 2018.

[132] S. J. Ha, J. Lee, K.-M. Song, Y. H. Kim, N. H. Lee, and S. K. Jung, "Ultrasonicated Lespedeza cuneata extract prevents TNF- $\alpha$-induced early atherosclerosis in vitro and in vivo," Food \& Function, vol. 9, no. 4, pp. 2090-2101, 2018.

[133] O. Güçlü, O. Doğanlar, V. Yüksel, and Z. B. Doğanlar, "FOLFIRI-mediated toxicity in human aortic smooth muscle cells and possible amelioration with curcumin and quercetin," Cardiovascular Toxicology, vol. 20, no. 2, pp. 139-154, 2020.

[134] M. Zhu, J. Li, K. Wang, X. Hao, R. Ge, and Q. Li, "Isoquercitrin inhibits hydrogen peroxide-induced apoptosis of EA.hy926 cells via the PI3K/Akt/GSK3 $\beta$ signaling pathway," Molecules, vol. 21, no. 3, p. 356, 2016. 